\title{
Molecular typing of Mycobacterium spp. isolates from Yemeni tuberculosis patients
}

\author{
A.A. Al-Mahbashi, ${ }^{1}$ M.M. Mukhtar ${ }^{2}$ and E.S. Mahgoub ${ }^{3}$
}

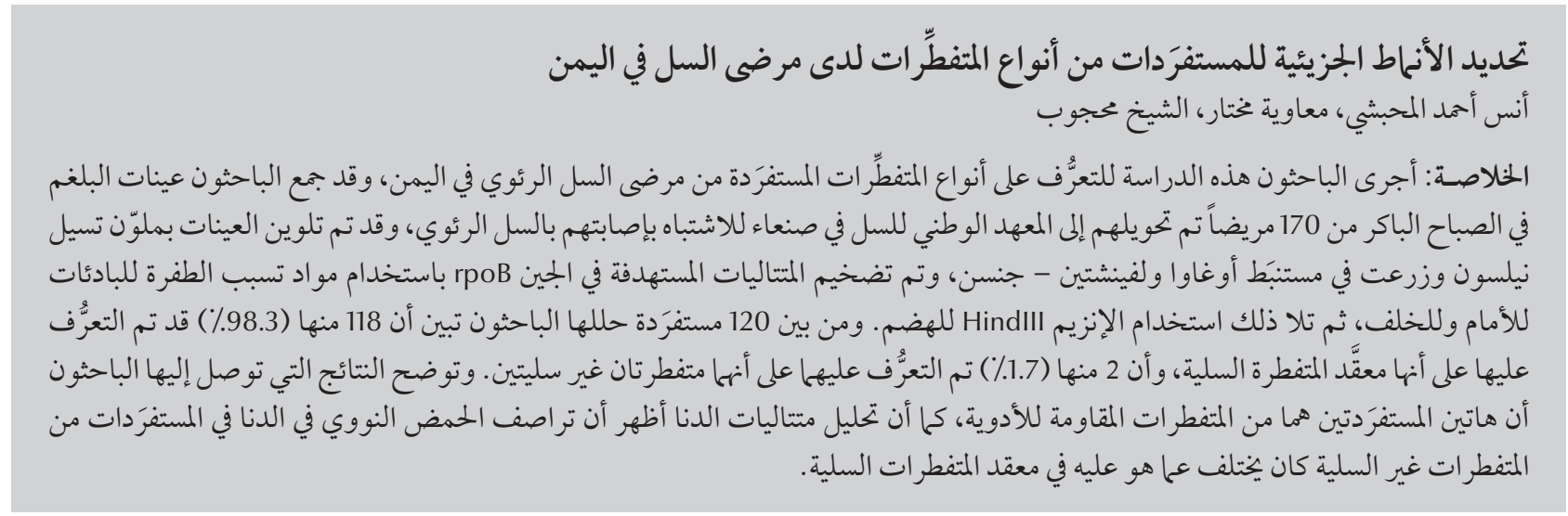

ABSTRACT This study was done to characterize at the species level Mycobacterium spp. isolates from Yemeni pulmonary tuberculosis patients. Early-morning sputum samples were collected from 170 patients referred to the National Tuberculosis Institute in Sana'a city with suspected pulmonary tuberculosis. Samples were processed with Ziehl-Neelsen stain and cultured in Ogawa and Lowenstein-Jensen media. The rpoB gene target sequence was amplified using mutagenesis forward and reverse primers followed by HindIII enzyme digestion. Of the 120 isolates analysed, 118 (98.3\%) were identified as M. tuberculosis complex and 2 (1.7\%) were identified as mycobacteria other than $M$. tuberculosis. The results showed that those 2 isolates were multi-drug resistant and the DNA sequencing analysis showed that the alignment of nucleic acid of DNA in isolates of mycobacteria other than M. tuberculosis was different from that of M. tuberculosis complex.

Typage moléculaire des isolats de Mycobacterium spp. prélevés chez des patients yéménites atteints de tuberculose

RÉSUMÉ La présente étude a été menée afin de caractériser l'espèce des isolats de Mycobacterium spp. prélevés chez des patients yéménites atteints de tuberculose. Des échantillons d'expectoration ont été prélevés tôt le matin chez 170 patients qui avaient été orientés vers I'Institut national de la tuberculose de la ville de Sanaa pour suspicion de tuberculose pulmonaire. Les échantillons ont été traités par coloration de Ziehl-Neelsen et mis en culture sur milieux Löwenstein-Jensen et Ogawa. La séquence cible du gène rpoB a été amplifiée selon la méthode des amorces mutagènes directe et inverse suivie par une digestion par l'enzyme HindIII. Sur les 120 isolats analysés, 118 (98,3\%) ont été identifiés comme appartenant au complexe M. tuberculosis et 2 (1,7\%) comme étant des mycobactéries d'un autre type que $M$. tuberculosis. Nos résultats ont révélé que ces deux isolats étaient pharmacorésistants tandis que l'analyse des séquences d'ADN a montré que l'alignement d'acide nucléique dans les isolats des mycobactéries d'un autre type que $M$. tuberculosis était différent de celui du complexe M. tuberculosis.

'Department of Microbiology, Faculty of Science, University of Sana'a, Sana'a, Yemen.

2Institute of Endemic Disease; ${ }^{3}$ Department of Microbiology and Parasitology, Faculty of Medicine, University of Khartoum, Khartoum, Sudan (Correspondence to E.S. Mahgoub: mahgoubsh@gmail.com).

Received: 04/06/12; accepted: 25/09/12 


\section{Introduction}

Tuberculosis (TB) is a disease of major public health concern worldwide. It is a bacterial infectious disease that is considered the second most important cause of death due to an identifiable infectious agent [1]. Approximately one-third of the world's population is infected with latent TB and $5 \%-10 \%$ of this population will develop active stages of the disease during their life time [2].

$\mathrm{TB}$ is a highly transmissible disease and infection can occur via inhalation of droplet particles aerosolized from persons infected with Mycobacterium tuberculosis or by consumption of milk infected with bovine M. bovis. The disease can infect humans and animals, with outcomes ranging from localized lesions to disseminated disease. The genus Mycobacterium comprises more than 70 species, some of which are potentially pathogenic to humans and animals and some of which are saprophytic. Mycobacteria that cause TB in mammals form the Mycobacterium tuberculosis complex (MTC) and include $M$. tuberculosis, $M$. africanum, $M$. bovis or M. bovis BCG, M. microtti and M. canetti. Other forms of mycobacteria that are considered opportunistic are termed mycobacteria other than Mycobacterium tuberculosis (MOTT) [3].

Yemen is one of the poorest of the world's low-income countries and $\mathrm{TB}$ is one of the most infectious diseases that are endemic in the Yemeni population. The absolute number of TB cases in Yemen is not known, but 37000 cases were recorded as under treatment throughout the country in the year 2002 [4]. The main objective of this study was to use molecular techniques to identify and characterize Mycobacterium spp. isolated from pulmonary $\mathrm{TB}$ patients in Yemen.

\section{Methods}

\section{Sample collection}

The study was conducted on patients referred to the National Tuberculosis Institute in Sana'a city with suspected pulmonary TB based on their presentation with cough more than 2 weeks. The Institute is a specialist referral centre for $\mathrm{TB}$ diagnosis and therapy and is situated in Sana'a the capital city of Yemen. The Institute receives TB patients from all regions of Yemen and provides free treatment.

An early-morning sputum sample was collected from 170 patients into wide-mouthed plastic containers. Baseline data of the patients was collected by completion of a questionnaire administered during the collection of samples. Samples were collected between January 2004 and October 2005 and the study was completed in 2008.

The study was approved by the University of Sana'a ethics committee and consent was obtained from the participants before their enrolment in the study.

\section{Laboratory methods}

Antibiotic sensitivity testing, using standard methods, was carried out on cultures from all 170 samples. For cost reasons, PCR was done on only 120 of the samples.

\section{Staining and culture methods}

Sputum samples were treated with $4 \%$ $\mathrm{NaOH}$ and stained by Ziehl-Neelsen stain to detect acid-fast bacilli [5]. The sputum samples were cultured on a special egg-based solid medium (Ogawa medium) according to the procedures of the Japan International Cooperation Agency [6]. Typically growth of Mycobacteria spp. appears within 3-4 weeks. The colonies are buff in colour with a dry and friable surface and irregular edges.

\section{DNA extraction}

Two colonies were taken from the culture medium and placed in 100 $\mu \mathrm{L}$ of sterile distilled water; $100 \mu \mathrm{L}$ of phenol-chloroform reagent was added and the mixture was vortexed for about $10 \mathrm{~s}$ and heated at $80^{\circ} \mathrm{C}$ for $20 \mathrm{~min}$. The mixture was stored at $-20^{\circ} \mathrm{C}$ in microcentrifuge tubes (free from DNA or RNA) until needed [7].

\section{Polymerase chain reaction technique}

Primers specific for the rpoB gene, encoding the B-subunit of RNA polymerase (rpoB DNA, 342-360 base pairs) was the target region for amplification and identification of $M y$ cobacterium spp. [8]. The polymerase chain reaction (PCR) mixture was prepared as follows: distilled water $5.0 \mu \mathrm{L}$, sample DNA $4.0 \mu \mathrm{L}$, PCR buffer $2.5 \mu \mathrm{L}, \mathrm{PCR} \mathrm{MgCl}_{2} 2.0 \mu \mathrm{L}$, PCR dNTP $2.5 \mu \mathrm{L}$, primers $3 \mu \mathrm{L}$, Tag polymerase $1.0 \mu \mathrm{L}$. The PCR mixture was gently mixed and amplified using a thermocycler (Perkin Elmer) adjusted to the cycling programme for $30 \mathrm{cy}$ cles. The sequence of $r p o B$ primers for the mutagenesis forward primer was 5'-CGA CCA CTT CGG CAA CCG-3' and for the mutagenesis reverse primer was 5'-TCG ATC GGG CAC ATC CGG-3'.

\section{Restriction fragment length polymor- phism (RFLP)}

Following amplification of the rpoB gene the product was subjected to digestion by HindIII restriction enzymes (Roche) as follows: $15 \mu \mathrm{L}$ from PCR product was pipetted into PCR tubes, $2 \mu \mathrm{L}$ of enzyme was added to the tube, $2 \mu \mathrm{L}$ of enzyme buffer was also added to the tube, then $1 \mu \mathrm{L}$ of distilled water was added to the mixture and mixed well [9].

\section{DNA sequencing analysis}

PCR-amplified DNA of the drugresistant isolates was commercially 
sequenced by Macrogen Company using the BigDye terminator cycling and universal primers.

\section{Results}

The age of the whole sample of 170 patients ranged between $12-70$ years old, and the largest proportion was in the age group 20-30 years (Table 1). There were significantly more males $(117,69 \%)$ than females $(53,31 \%)$ $(P<0.05)$.

After culture and sensitivity testing of isolates, 15 antibiotic resistant isolates were found: 5 (33.3\%) were resistant to 1 drug, $4(26.6 \%)$ to 2 drugs, $4(26.6 \%)$ to 3 drugs and 2 (13.3\%) to 4 drugs. The resistance data were as follows: isoniazid 14/15 (93\%), rifampicin 8/15 (53\%), streptomycin 5/15 (33\%) and ethambutol $6 / 15(40 \%)$.

Our results showed that mycobacterial DNA was amplified successfully using the relevant primers and the size of DNA was 360 bp compared with the molecular weight marker (100 bp) (Figure 1).

The PCR-RFLP results showed that $118 / 120$ (98.3\%) of the isolates were MTC, whereas 2/120 (1.7\%) were MOTT (Figure 2A and B).

The DNA sequencing analysis results showed that the DNA sequence of MTC strains were different from MOTT strains (Figure 3).

\section{Discussion}

A recent health report on Arab countries by the World Health Organization declared that TB was an important public health problem in the 19 Arab countries of the Eastern Mediterranean Region, affecting 240000 people with 53000 deaths everyyear; $85 \%$ of the deaths occurred in adults [10]. In Yemen, TB is considered one of the major infectious

\begin{tabular}{lcc}
\hline $\begin{array}{l}\text { Table } 1 \text { Age and sex distribution of the study patients who were sputum-smear } \\
\text { positive for tuberculosis }\end{array}$ & No. \\
\hline Variable & & $\%$ \\
Age group (years) & 40 & 24 \\
$10-<20$ & 67 & 39 \\
$20-<30$ & 27 & 16 \\
$30-<40$ & 18 & 11 \\
$40-<50$ & 10 & 6 \\
$50-<60$ & 8 & 5 \\
$>60$ & 117 & 69 \\
Sex & 53 & 31 \\
Male & 170 & 100 \\
Female & & \\
Total & & \\
\hline
\end{tabular}

diseases recorded in the national disease list [11]. A rapidly increasing population, poor quality health services, very low annual income of individuals and the whole country's poor economic status are the most important factors responsible for the high incidence of TB in the country [12].

In the present study 170 patients were recruited who were suspected of having pulmonary TB based on their presentation with cough more than 2 weeks. The age of the patients ranged between $12-70$ years old, and the highest prevalence was among the age group 20-30 years. These results are in agreement with previous reports from the national disease surveillance infectious diseases centre and the Ministry of Health $[11,12]$. As previously reported, in this study males were significantly more affected than females [13]. In Yemen the higher rate of TB in males may be attributed to the different habits of males, especially smoking the waterpipe (nargile or mada'a), which is usually shared between different persons. Another prevalence study on pulmonary $\mathrm{TB}$

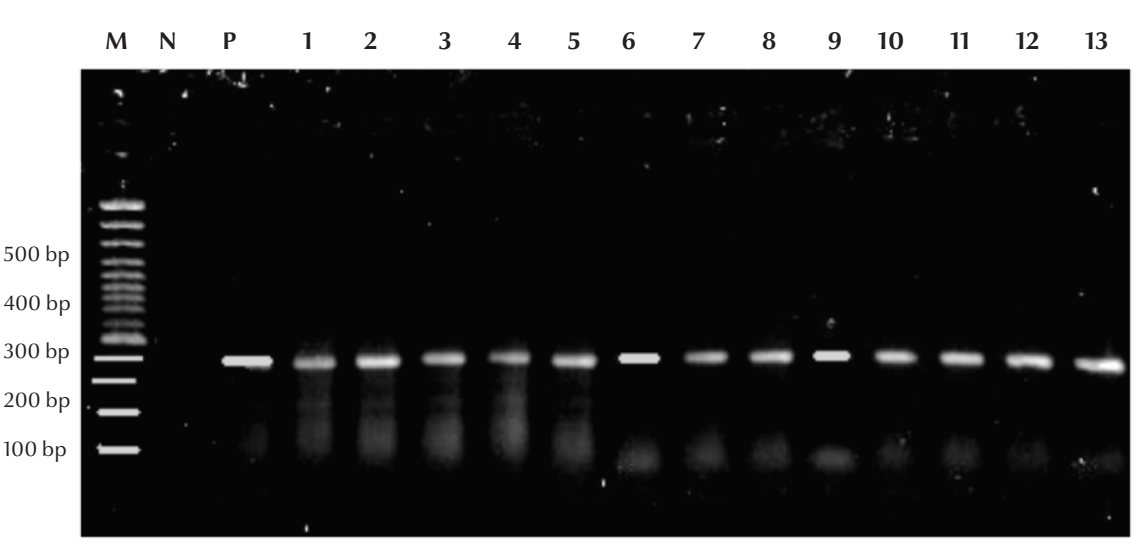

Figure 1 Polymerase chain reaction assay results using the MF and MR primers for detection and amplification of the Mycobacterium rpoB gene from the isolates with leader marker (100 bp) to detect the size of amplified DNA $M=$ molecular weight control marker (100 bp); $P=$ positive control; $N=$ negative control; lanes 1-13 from patient samples 


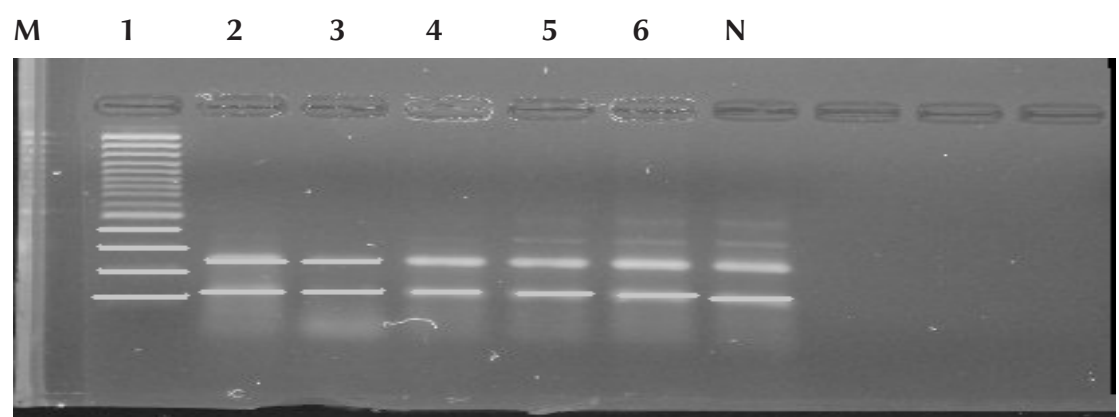

Figure 2A Polymerase chain reaction-restriction fragment length polymorphism assay using restriction enzymes of confirmed tuberculosis patients; lanes 1,2,3,4,5,6 were Mycobacterium tuberculosis complex isolates that showed 2 fragments. $\mathrm{M}=$ control marker $100 \mathrm{bp} ; \mathrm{N}=$ negative control

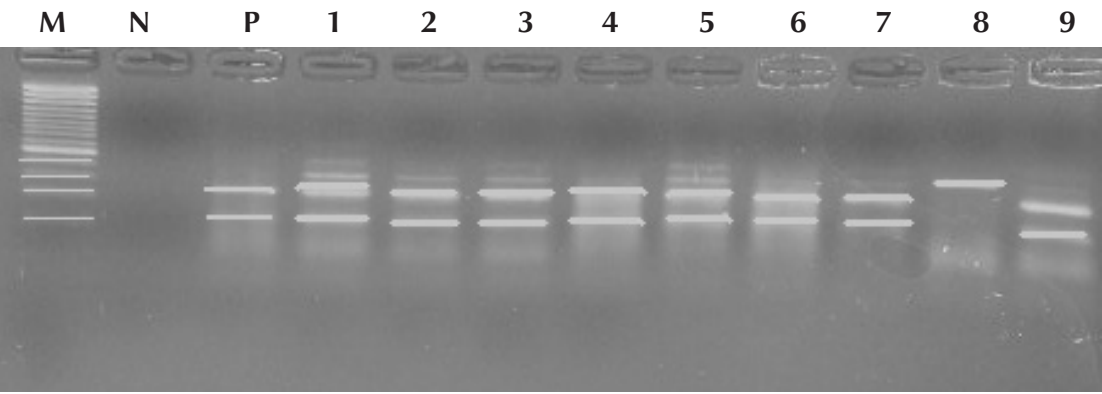

Figure 2B Polymerase chain reaction-restriction fragment length polymorphism assay using restriction enzymes of confirmed tuberculosis patients; lanes 1,2,3,4,5,6,7,9 were Mycobacterium tuberculosis complex isolates that showed 2 fragments, whereas lane 8 is Mycobacteria other than M. tuberculosis that showed 1 fragment. $\mathrm{M}$ = control marker $100 \mathrm{bp} ; \mathrm{N}=$ negative control; $\mathrm{P}$ = positive control

1- ACCA-GCCAGCTGAGCCAATTCATGGACCAGAACAACCCGCTGTCGGGGTTGACCGACAA

2- ACCA-TCCAGCTGAGCCAATTCATGGACCAGAACAACCCGCTGTCGGGGTTGACCCACAA

3- ACCA-GCCAGCTGAGCCAATTCATGGACCAGAACAACCCGCTGTCGGGGTTGACCCACAA

4- ACCA-GCCAGCTGAGCCAATTCATGGACCAGAACAACCCGCTGTCGGGGTTGACCCACAA

5- ACCA-GCCAGCTGAGCCAATTCATGGACCAGAACAACCCGCTGTCGGGGTTGACCCACAA

6- ACCA-GCCAGCTGAGCCAATTCATGGACCAGAACAACCCGCTGTCGGGGTTGACCCACAA

7- ACCA-GCCAGCTGAGCCAATTCATGGACCAGAACAACCCGCTGTCGGGGTTGACCCACAA

8- ACCA-GCCAGCTGAGCCAATTCATGGACCAGAACAACCCGCTGTCGGGGTTGACCCACAA

9- ACCA-GCCAGCTGAGCCAATTCATGGACCAGAACAACCCGCTGTCGGGGTTGACCCACAA

10- ACCA-GCCAGCTGAGCCAATTCATGGACCAGAACAACCCGCTGTCGGGGTTGACCCACAA

11- ACCA-GCCAGCTGAGCCAATTCATGGACCAGAACAACCCGCTGTCGGGGTTGACCCACAA

12- ACCA-GCCAGCTGAGCCAATTCATGGACCAGAACAACCCGCTGTCGGGGTTGACCCACAA 13- ACCGCGTCGTGTATGACTCTGTATACACAGAGGAGTCACGGCGCGCGTGGTGGTCTCCAT

Figure 3 DNA sequence analysis alignment showing the difference between nucleic acid of Mycobacterium tuberculosis complex (samples 1-12) and Mycobacteria other than M. tuberculosis (sample 13) attributed the low prevalence of TB among women to underdetection of TB in females because women often choose medical care providers operating outside the national TB control centres [14].

Routine sputum smears and Mycobacterium spp. cultures confirmed the presence of acid-fast bacilli in the 170 sputum samples examined. However, acid-fast staining does not identify the Mycobacterium to the species level. In addition the time required to detect the organism by routine culture is approximately $4-8$ weeks. PCR assay was therefore used to characterize 120 of the isolates. The rpoB gene was successfully amplified in all isolates and enabled identification of $\mathrm{Myco}-$ bacterium spp. following restriction of the PCR product by HindIII restriction enzyme that produced 2 DNA fragments in the amplicons of $M$. tuberculosis.

The PCR-RFLP results identified 98.3\% of isolates as MTC and $1.7 \%$ samples as MOTT. Interestingly the MOTT isolates were resistant to isoniazid, rifampicin and streptomycin. MOTT have been reported to cause infection in humans and to complicate treatment regimens since they may not respond to routinely used anti-TB drugs [15-17]. Based on the results of this study we recommend the use of molecular techniques for identification of the Mycobacterium spp. before initiation of treatment.

\section{Acknowledgements}

Funding: This research was supported by the Ministry of Higher Education of Yemen as part of a $\mathrm{PhD}$ degree for the first author.

Competing interests: None declared. 


\section{References}

1. Tiruviluamala P, Reichman LB. Tuberculosis. Annual Review of Public Health, 2002, 23:403-426.

2. Jones-Lopez EC, Ellner JJ. Tuberculosis and atypical mycobacterial infections. In: Guerrant RL, Walker DH, Weller PF, eds. Tropical infectious diseases: principles pathogens and practice. New York, Elsevier, 2011 (Chapter 36).

3. Annual heath report. National tuberculosis control programme. Sana'a, Yemen, Ministry of Health, 2004.

4. Edsel M, Gregory SC, Robert AS. Mycobacterium other than tuberculosis (MOTT) infection: an emergency disease in infliximab treated patients. Journal of Infection, 2007, 10:1-4.

5. Cheesbrough M. District laboratory practice in tropical countries. Volume 2. Cambridge, Cambridge University Press, 2000:207-213.

6. Kawai M, Fujiki A. Minimum essentials of laboratory procedure for tuberculosis control. Tokyo, Japan Anti-Tuberculosis Association, Research Institute of Tuberculosis in Japan, 1996.

7. Yates MD, Drobniewski FA, Wilson.SM. Evaluation of a rapid PCR-based epidemiological typing method for routine studies of Mycobacterium tuberculosis. Journal of Clinical Microbiology, 2002, 40(2):712-714.

8. Kim BJ et al. Differentiation of mycobacterial species by PCR-restriction analysis of DNA (342 base pairs) of the RNA polymerase gene (rpoB). Journal of Clinical Microbiology, 2001, 39:2102-2109.

9. Kim BJ et al. Identification of mycobacterial species by comparative sequence analysis of the RNA polymerase gene (rpoB). Journal of Clinical Microbiology, 1999, 37:1714-1720.
10. Tuberculosis. In: Overview of child health in Arab countries, 2nd ed. Alexandria, Egypt, World Health Organization Regional Office for the Eastern Mediterranean, 2002.

11. Tuberculosis infection: disease surveillance of infectious disease. Sana'a, Yemen, Ministry of Health and World Health Organization Country Office, 2000:49-52.

12. National tuberculosis programme. Tuberculosis in Republic of Yemen. Sana'a, Yemen, Ministry of Health, 1996.

13. Abassi A, Mansourian AR. Efficacy of DOTS strategies in treatment of respiratory tuberculosis in Gorgan, Islamic Republic of Iran. Eastern Mediterranean Health Journal, 2007, 13(3):664-669.

14. Thorson A et al. Do women with tuberculosis have a lower likelihood of getting diagnosed? Prevalence and case detection of sputum smear positive pulmonary TB, a populationbased study from Vietnam. Journal of Clinical Epidemiology, 2004, 57(4):398-402.

15. Kearns AM et al. Epidemiology and molecular typing of an outbreak of tuberculosis in a hostel for homeless men. Journal of Clinical Pathology, 2000, 53(2):122-124.

16. Sharaf-Eldin GS et al. Molecular analysis of clinical isolates of Mycobacterium tuberculosis collected from patients with persistent disease in the Khartoum region of Sudan. Journal of Infection, 2002, 44:244-251.

17. Sanguinetti $M$ et al. Routine use of PCR-reverse cross-blot hybridization assay for rapid identification of Mycobacterium species growing in liquid media. Journal of Clinical Microbiology, 1998, 36:1530-1533. 